\title{
Preparation of Microcapsules of Slow-Release NPK Compound Fertilizer and the Release Characteristics
}

\author{
Wancheng Pang, ${ }^{a, \#}$ Dejia Hou, ${ }^{a}$ Huan Wang, ${ }^{a}$ Shu Sai, ${ }^{a}$ Baorui Wang,,${ }^{a, \#}$ Jingwen Ke, ${ }^{a}$ \\ Gaobing Wu, ${ }^{b}$ Qing Li ${ }^{*, a}$ and Mark T. Holtzapple ${ }^{c}$
}

${ }^{a}$ College of Science, Huazhong Agricultural University, 430070 Wuhan, PR China

${ }^{b}$ College of Plant Science and Technology, Huazhong Agricultural University, 430070 Wuhan, PR China

'Department of Chemical Engineering, Texas A\&M University, 77843 College Station, USA

\begin{abstract}
In this study, a novel type of slow-release fertilizer (SRF) was synthesized through lignin-based microcapsules. $\mathrm{K}_{2} \mathrm{HPO}_{4}$ and urea were coated by lignin and formaldehyde to prepare microcapsules of NPK compound SRF. The slow-release performance was measured by determining the NPK contents in water solution and soil column leaching. The release amounts of N, P and K after 5 days were $95.39,95.28$ and $96.75 \%$ in water, and $83.35,96.62$ and $90.75 \%$ in soil, respectively. The properties of SRF were analyzed by Fourier transform infrared spectroscopy, thermogravimetry and scanning electron microscopy. NPK release from the SRF was promoted by higher temperature and acid environment, but inhibited by alkaline environment. The first order kinetics equation provides the best correlation to describe nutrient release characteristics. The results indicated that SRF have good slow-release properties and are cost-saving and environment-friendly, and thus can efficiently improve the utilization efficiency of fertilizers in agricultural production.
\end{abstract}

Keywords: microcapsules, lignin based, urea-formaldehyde resin, NPK compound fertilizer, slow release fertilizer

\section{Introduction}

Due to the rapid growth of world population, modern agriculture plays a critical role in meeting the demand for foods and other agro-products. ${ }^{1}$ Better agricultural conditions such as soil fertility always involve greater inputs of fertilizers. ${ }^{2}$ Fertilizers and water are the most important elements in agricultural production. Nitrogen $(\mathrm{N})$, phosphorus $(\mathrm{P})$ and potassium $(\mathrm{K})$ are three major elements required for plants. Currently, the most important feature of commercial fertilizers is instant dissolution. ${ }^{3}$ However, because the release rate per unit time of nutrients is usually much higher than the adsorption rate by the crops, traditional chemical fertilizers often cause resource waste, environmental pollution and other problems. Moreover, the long-term use of these fertilizers may cause soil compaction and decrease of crop yields. ${ }^{4}$ Slow-release fertilizers (SRFs) may be a promising approach to alleviate such problems and improve nutrient utilization efficiency at the same time. ${ }^{5}$ SRFs are designed to gradually release nutrients at a rate

*e-mail: liqing@mail.hzau.edu.cn

\#These authors contributed equally to this work. in accordance with the nutrient requirement of the plants, which is conducive to the reduction of nutrient loss. ${ }^{6}$ The advantages of using SRFs instead of conventional fertilizers are various, such as higher efficiency of the fertilizer, the continuous supply of nutrients for a prolonged period and lower nutrient losses due to volatilization and leaching. ${ }^{7}$

Usually, resins and thermoplastic materials are used as organic polymer coatings for fabrication of SRFs, such as polysulfone, wax, polyacrylonitrile, and cellulose acetate. ${ }^{8}$ However, their high production costs and nonbiodegradability largely hinder their extensive application in agriculture field. ${ }^{9}$ Therefore, due to its abundance, nontoxicity, low cost and biodegradability, biomass has been widely used as SRF material. França et al. ${ }^{10}$ used rice husk ash as the raw material to prepare a slow-release fertilizer containing silicon and potassium. Wen et al. ${ }^{11}$ reported the synthesis of a corncob-based semi-interpenetrating polymer network slow-release nitrogen fertilizer. In addition, they used cotton straw and bentonite as the polymer matrix synthesis biochar-based slow-release nitrogen fertilizers. ${ }^{12}$

Lignin, a main component of lignocellulosic biomass, is one of the most abundant natural and biodegradable polymers. It is a waste material that may be ideal 
for application to soil and is one of the most slowly decomposing components of dead vegetation, contributing a major fraction of the material that becomes humus as it decomposes. The resulting soil humus, in general, increases the photosynthetic productivity of plant. ${ }^{13}$ Behin and Sadeghi ${ }^{14}$ coated granular urea with a thin layer of synthesized acetylated lignin using a fluidizedbed technique. Li et al..$^{15}$ employed lignin and clay to prepare composite materials with the property of slow release of urea. Based on methylolated lignin and urea/hydroxymethylurea/urea-formaldehyde polymer, Jiao et al. ${ }^{16}$ prepared a new type of slow-release threedimensional network polymer materials. Although these lignin-based SRFs are able to effectively increase urea-use efficiency, most of them only focus on urea as a nutrient for SRFs. Thus, to improve the utilization of multiple nutrients at the same time, it is important to prepare lignin-based slow-release compound fertilizers to reduce the frequency of fertilizer application.

Microencapsulation involves coating or entrapping of a core material with a polymeric material to generate microspheres within the size range of 1-1000 $\mu \mathrm{m}$, which has been defined as the technology of packaging solid, liquid and gaseous materials in small capsules that release their contents at controlled rates over prolonged periods of time. ${ }^{17}$ This versatile technology has been used in many fields, such as drugs, energy and catalyst. Due to its advantage of controlled release, microcapsule technology shows promising potentials of application in agriculture. ${ }^{18}$ Therefore, loading of nutrients in biodegradable microcapsules may enable the controllable release of nutrients, which is conducive to the long-term effects of fertilizers. ${ }^{19}$

Based on the above studies of slow-release fertilizers, we prepared urea-formaldehyde resin microcapsules by an in situ polymerization method in this study. Because lignin from plants can be used as a sustained release material and can finally be recycled into the soil, we applied lignin as the raw material for the production of SRF. The chemical composition, phase transition characteristics and morphology of the microcapsules were characterized by Fourier transform infrared spectroscopy (FTIR), thermogravimetric analysis (TGA) and scanning electron microscopy (SEM). Slow release polymers could reduce pollution and other side effects compared with conventional fertilizer.

\section{Experimental}

\section{Materials}

Lignin was bought from a paper mill company, Shandong, China. Urea, formaldehyde, $\mathrm{K}_{2} \mathrm{HPO}_{4} \cdot 3 \mathrm{H}_{2} \mathrm{O}$, acetate, sodium acetate, sodium bicarbonate, sodium carbonate and $\mathrm{NaOH}$ were purchased from Guoyao Jituan Chemical Reagent Co., Ltd. (Shanghai, China). All reagents were of analytical grade and all solutions were prepared with distilled water. All the materials used were available from commercial sources and used as received.

\section{Synthesis of SRF}

In this procedure, slow-release lignin-based microcapsules were synthesized by mixing $120.0 \mathrm{~g}$ formaldehyde, $250.0 \mathrm{~g}$ urea, and $50.0 \mathrm{~g}$ lignin into a $1000 \mathrm{~mL}$ round bottom flask at $80{ }^{\circ} \mathrm{C}$ with stirring of $80 \mathrm{rpm}$, and maintained for $120 \mathrm{~min}$. Then, $100 \mathrm{~mL}$ of $\mathrm{K}_{2} \mathrm{HPO}_{4} \cdot 3 \mathrm{H}_{2} \mathrm{O}\left(0.8 \mathrm{~g} \mathrm{~mL}^{-1}\right)$ solution was added and mixed at $80 \mathrm{rpm}$ for $120 \mathrm{~min}$, followed by $10 \mathrm{~mL}$ of $4 \%(\mathrm{~m} / \mathrm{m})$ $\mathrm{NaOH}$ for another $10 \mathrm{~min}$ mixing. Finally, the resulting products were oven-dried at $50{ }^{\circ} \mathrm{C}$ until a constant weight, sealed and stored for future use (Figure 1).

\section{Characterization of SRF}

The ingredients of SRF were analyzed using an FTIR spectrophotometer (American Thermo Nicolet, model Nicolet IS50). The dried sample of SRF and KBr powder were mixed and ground, and the pallets were scanned in the wavenumber range of $4000-400 \mathrm{~cm}^{-1}$. The SRF was analyzed using a TGA (Germany, model DSC200PC); $3 \mathrm{mg}$ sample was placed in an alumina cup and weight was recorded at the heating rate of $10{ }^{\circ} \mathrm{C} \mathrm{min}-1$ over the range of $25-800{ }^{\circ} \mathrm{C}$ to test the thermal stability of the material under flowing nitrogen. The topographic images were recorded with SEM (Zeiss SIGMA, UK) after coating of the samples with gold film.

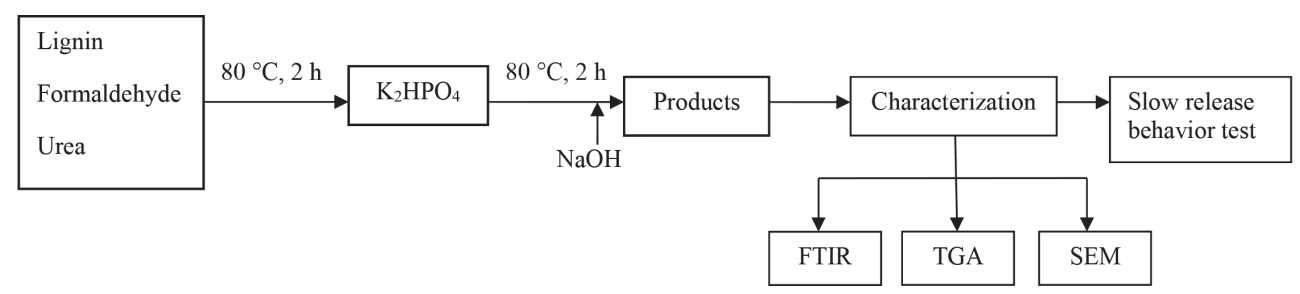

Figure 1. Schematic diagram of preparation and characterization of SRF. 


\section{Slow release behavior of SRF}

\section{Slow release behavior of SRF in water}

Slow release behavior was examined to determine the nutrient leaching pattern of the SRF in water. Accurately weighed SRF (about $10 \mathrm{~g}$ ) was immersed into $200 \mathrm{~mL}$ water and allowed to soak at room temperature for 56 days. Sampling was conducted every two days during the first 2 weeks, and then once a week. The nutrient release rate was calculated using the following equation:

$\mathrm{W}_{\mathrm{t}}(\%)=\left(\mathrm{M}_{\mathrm{t}} / \mathrm{M}_{0}\right) \times 100$

where $M_{t}(g)$ and $M_{0}(g)$ represent the mass of the cumulative released nutrients and mass of the total corresponding nutrient of the SRF, respectively, and $\mathrm{W}_{\mathrm{t}}(\%)$ is the cumulative nutrient release rate.

The collected samples (from above experiments) were analyzed for $\mathrm{K}$ content by flame atomic absorption spectrometer (FAAS), N content by Kjeltec auto analyzer, and $\mathrm{P}$ content by UV visible spectrophotometer.

\section{Slow release behavior of SRF in soil}

To study the slow release behavior of SRF in soil, the following experiment was carried out: SRF (about $10 \mathrm{~g}$ ) was well mixed with $300 \mathrm{~g}$ dry soil (below $2 \mathrm{~mm}$ in diameter) and kept in a $500 \mathrm{~mL}$ plastic beaker properly covered and incubated for 56 days at room temperature. Throughout the experiment, the soil was maintained at 50\% (adding $40 \mathrm{~mL}$ water to $300 \mathrm{~g}$ soil) water-holding capacity by periodically weighing and adding distilled water if necessary. The experimental blank using just soil sample (300 g) was run under the same set of conditions. The calculation of release rate and $\mathrm{N}, \mathrm{P}$ and $\mathrm{K}$ content tests were the same as those for the slow release behavior in water.

\section{Effects of temperature and $\mathrm{pH}$ on the solubility of SRF}

SRF (about $10 \mathrm{~g}$ ) was added into bottles with $500 \mathrm{~mL}$ buffer at $\mathrm{pH}$ of 5, 7 and 9, respectively. The bottles were then placed in incubators at 5,25 and $45^{\circ} \mathrm{C}$ (three bottles of different $\mathrm{pH}$ for each temperature). The remaining SRF in the bottles was taken out every day, and then dried at $100{ }^{\circ} \mathrm{C}$ to a constant weight to be weighed for calculating the cumulative release rate. The buffer was replaced every day with new buffer. The weight loss rate was calculated using the following equation:

$\mathrm{W}_{\mathrm{A}}(\%)=\left[\left(\mathrm{M}_{0}-\mathrm{M}\right) / \mathrm{M}_{0}\right] \times 100$

where $\mathrm{M}_{0}(\mathrm{~g})$ and $\mathrm{M}(\mathrm{g})$ represent the mass of the initial SRF and that of the remaining SRF, respectively, and $\mathrm{W}_{\mathrm{A}}(\%)$ is the weight loss rate.

\section{Statistical analysis}

The data were analyzed using Microsoft Excel and OriginPro 8.5 software. ${ }^{20}$ All the readings are reported as average of three.

\section{Results and Discussion}

\section{Chemical structure analysis of SRF by FTIR}

The FTIR spectra of lignin and SRF are presented in Figure 2. In the lignin spectra, peaks were observed at 3422 (stretching vibration of hydroxyl O-H), 2933 (stretching vibration of methyl and methylene C-H), 1577, 1414 (aromatic skeletal vibrations), 1338, 1187 (aromatic skeletal combined with O-H bending vibration), 1126 (breathing vibration of syringyl and condensed guaiacyl, guaiacyl ring breathing with $\mathrm{C}=\mathrm{O}$ stretching vibrations) and $1047 \mathrm{~cm}^{-1}$ (uncondensed guaiacyl), which are typical signals of lignin. ${ }^{21}$

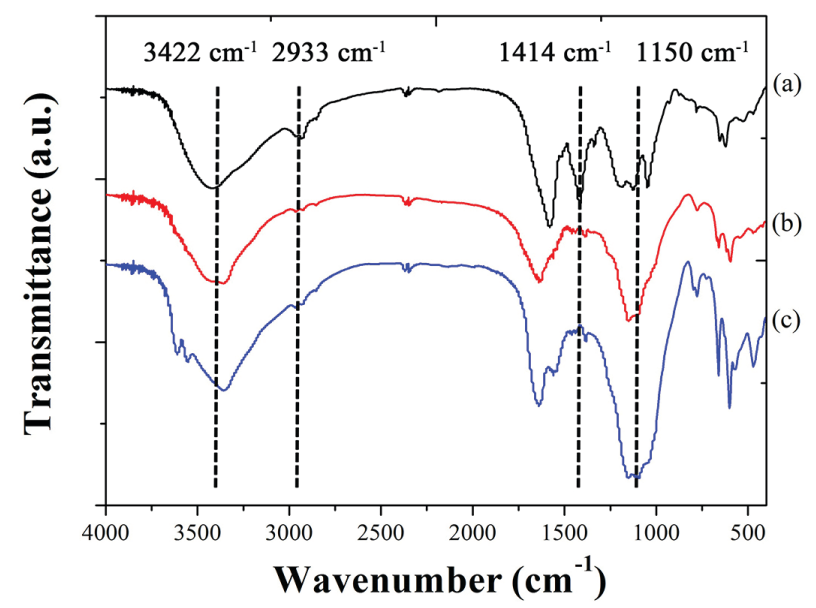

Figure 2. FTIR spectra of (a) lignin and SRF (b) before and (c) after nutrient release.

Compared with Figure 2a, Figure 2b exhibited an intensive characteristic absorption peak of SRF at $1150 \mathrm{~cm}^{-1}$. The intensity of the band at $2933 \mathrm{~cm}^{-1}$ decreased and the band at $1414 \mathrm{~cm}^{-1}$ disappeared. The band at $1150 \mathrm{~cm}^{-1}$ was assigned to hydroxymethyl groups, which were formed by electrophilic addition of formaldehyde and phenolic hydroxyl on lignin during the polymerization process. ${ }^{16}$ The weakening of stretching vibration of methyl and methylene $\mathrm{C}-\mathrm{H}$ and the disappearance of the absorption bands at 2933 and $1414 \mathrm{~cm}^{-1}$ might be caused by the decrease in the contents of methyl and methylene 
groups due to the introduction of formaldehyde or ureaformaldehyde. For SRF after nutrient release (Figure 2c), the absorbance at $1150 \mathrm{~cm}^{-1}$ obviously increased and other characteristic peaks did not show any changes, indicating that after nutrient release, the main residue of SRF was hydroxymethylated lignin. The above results suggested that the lignin was bound onto the SRF backbone after cross-linking reaction.

\section{Thermal gravimetric analysis}

The TG curves of lignin, SRF before and after nutrient release are depicted in Figure 3. The decomposition of lignin (Figure 3a) and SRF (Figure 3b) mainly occurred with a mass loss in the temperature range of 25 to $200{ }^{\circ} \mathrm{C}$ due to moisture loss and removal of light volatile components. The mass loss of SRF was higher than that of lignin in the temperature range of 200 to $400{ }^{\circ} \mathrm{C}$, which could be attributed to the continuous vaporization and decomposition of urea and $\mathrm{K}_{2} \mathrm{HPO}_{4}$ besides the thermal decomposition of lignin. The mass loss in the temperature range of 400 to $700{ }^{\circ} \mathrm{C}$ could be assigned to the further thermal degradation of lignin and the main-chain decomposition of the polymers. Significant mass loss occurred again after $700{ }^{\circ} \mathrm{C}$, and the continuous increase in mass loss rate could be attributed to the cracking reaction of small molecules after pyrolysis of lignin and SRF. In the end, the residual percentage of SRF was about $52.62 \%$, which was higher than that of lignin (45.09\%), indicating that lignin had more condensed structure and better thermal stability after crosslinking reaction, which was conducive to the slow-release properties of fertilizers. ${ }^{16}$

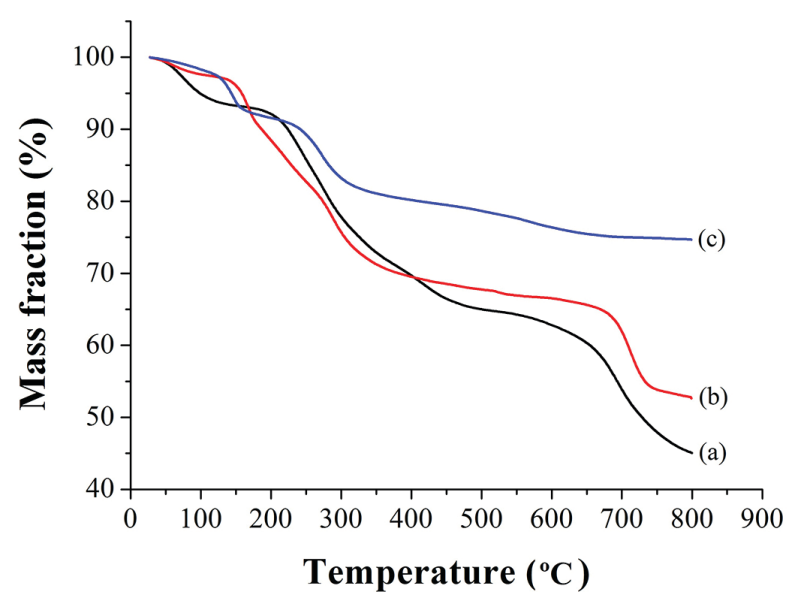

Figure 3. TG curves of (a) lignin and SRF (b) before and (c) after nutrient release.

After nutrient release (Figure 3c), the mass loss of SRF mainly occurred at the temperature ranging from 25 to
$200{ }^{\circ} \mathrm{C}$ and 200 to $300{ }^{\circ} \mathrm{C}$, which was induced by moisture loss and removal of light volatile components as well as the thermal decomposition of lignin. At the temperature above $300{ }^{\circ} \mathrm{C}$, there was no obvious mass loss, which also manifested that the SRF nutrients were almost completely released after water soaking and the remaining residue was hydroxymethylated lignin.

\section{Morphology of SRF under SEM}

The surface morphologies of the samples are displayed in Figure 4. The microcapsules exhibited irregular globular shapes and were attached to SRF backbone (Figures $4 \mathrm{a}$ and $4 \mathrm{~b})$. At the same time, obvious adhesion and aggregation were observed for the microcapsules, which may be due to electrostatic adsorption on the surface of the microcapsules and intermolecular agglomeration during drying. ${ }^{22}$ As shown in Figure 4c, after nutrient release, SRF displayed an undulant and coarse surface and the microcapsules disappeared. These results demonstrated that after the uptake of a certain amount of water, the microcapsules were broken, followed by a burst release of nutrients.

\section{Slow release behavior of SRF}

One of the most important characteristics of the prepared SRF was its slow-release property. Hence, the slow-release characteristics of SRF in water and soil were determined to evaluate its application prospects in agriculture and horticulture. Figures $5 \mathrm{a}, 5 \mathrm{~b}$ and $5 \mathrm{c}$ show the slow release behaviors of N, P and K from SRF in water and soil, respectively.

The release of $\mathrm{N}, \mathrm{P}$ and $\mathrm{K}$ in water could be divided into two stages: a fast release in the first 14 days, during which the cumulative release rates of $\mathrm{N}, \mathrm{P}$ and $\mathrm{K}$ reached 94.39, 93.80 and $89.86 \%$, respectively; and a slower release in the remaining period, during which the cumulative release rates of N, P and K further increased to $95.39,95.28$ and $96.75 \%$ after 56 days, respectively. Here again, $\mathrm{N}$ and $\mathrm{P}$ were almost no longer released after 14 days, while there was still a slow release of $\mathrm{K}$.

In 56 days of experiment, the NPK release in soil exhibited the same trend (rapid release in the first 14 days and slow release thereafter) as observed in distilled water. By the $7^{\text {th }}, 14^{\text {th }}$ and $21^{\text {st }}$ day, the $\mathrm{N}$ release rates were 37.71 , 62.24 and $67.41 \%$ (Figure 5a); the P release rates were 53.36, 81.23 and $85.34 \%$ (Figure $5 \mathrm{~b}$ ); the $\mathrm{K}$ release rates were $42.28,74.21$ and $80.64 \%$ (Figure 5c), respectively. The cumulative release rates of $\mathrm{N}, \mathrm{P}$ and $\mathrm{K}$ respectively reached $83.35,96.62$ and $90.75 \%$ after 56 days. It is noteworthy that the release rate of $\mathrm{N}$ was significantly 


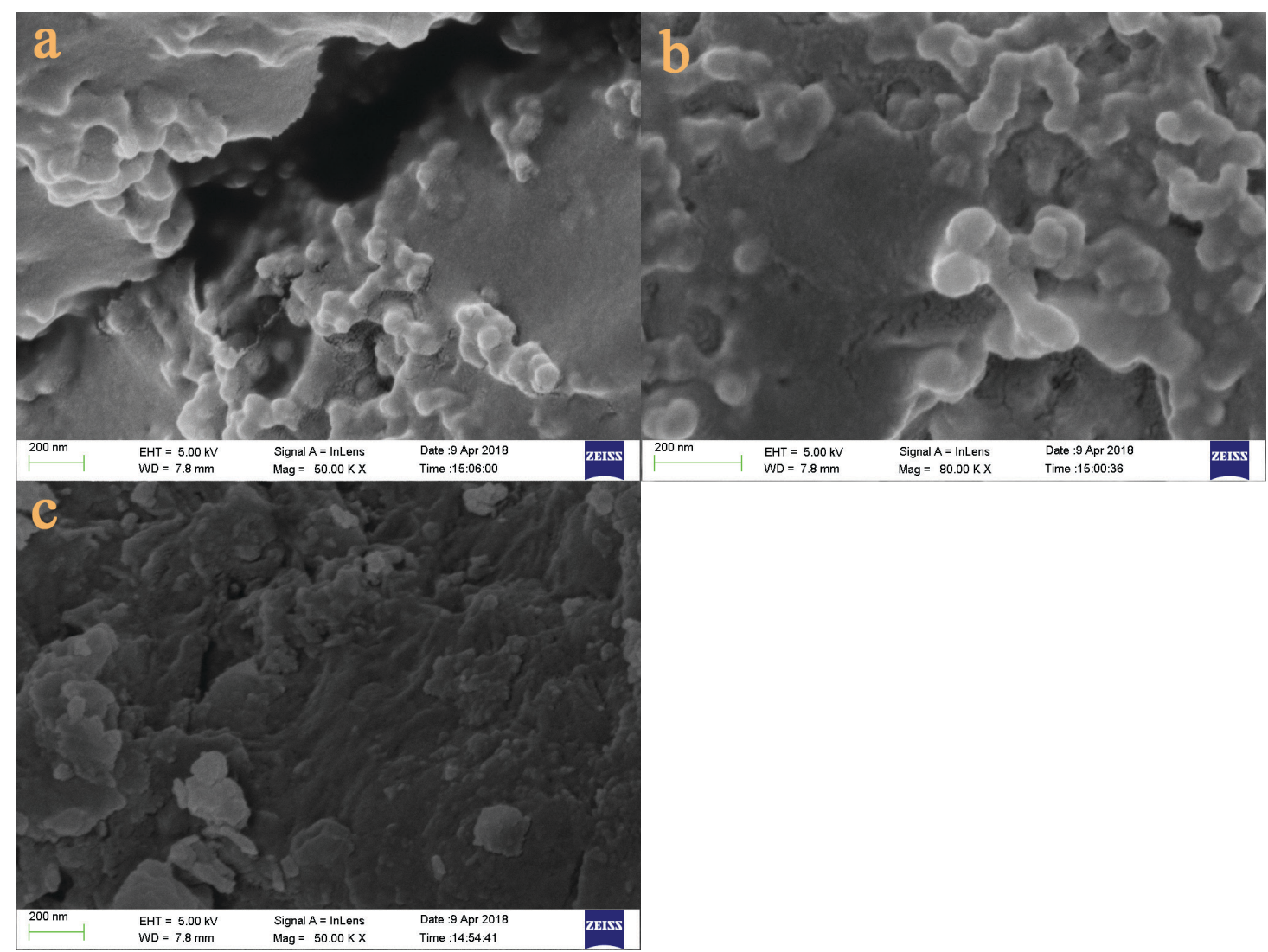

Figure 4. Comparison of SRF surface $(a, b)$ before and $(c)$ after nutrient release under SEM.
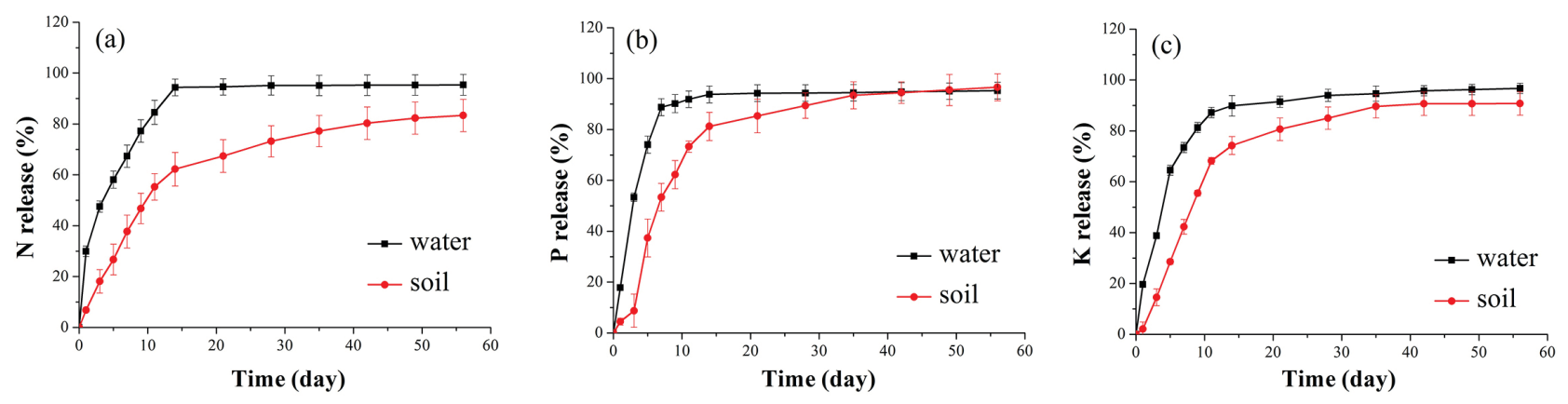

Figure 5. Release behaviors of nutrients (a) N; (b) P and (c) K from SRF under water and soil soaking.

lower compared with that of $\mathrm{P}$, which might be due to the additional $\mathrm{N}$ release from the gradual degradation of the lignin urea-formaldehyde polymers with increasing burying time when the SRF were applied into soil. Besides, the release rate of $\mathrm{K}$ was also significantly lower than that of $\mathrm{P}$. This difference may be attributed to the fact that lignin is a kind of macromolecular material composed of phenylpropane structural units, and contains more phenolic hydroxyl groups and alcoholic hydroxyl groups. These groups are mostly negatively charged groups that can be dissociated and can serve as cationic protective agents for maintaining ammonium, potassium and other cationic nutrients. ${ }^{23}$ More specifically, the molecular structure of
SRF might act as a physical barrier for the diffusion of $\mathrm{K}$, which would reduce the release rate of $\mathrm{K}$.

Influences of $\mathrm{pH}$ and temperature on nutrient release rate of SRF

The effects of temperature and $\mathrm{pH}$ on the slow release behaviors of SRF were investigated by weight loss method. With the extension of the dissolution time, the weight loss rate of SRF gradually increased. Similar to the release of various nutrient elements, SRF weight loss was also rapid at first, and then became slower in the remaining period. The rapid weight loss in the first 10 days could be attributed 
to the dissolution of nutrients and soluble part of the SRF, and the slow weight loss thereafter was due to the slow dissolution of the remaining insoluble materials in the SRF.

After dissolution for 56 days and when the temperature was 5,25 and $45{ }^{\circ} \mathrm{C}$, the weight loss rates of SRF were 66.16, 66.64 and $73.39 \%$ when $\mathrm{pH}=5$ (Figure 6a), 53.60, 59.90 and $62.44 \%$ when $\mathrm{pH}=7$ (Figure 6b), and 37.22, 38.10 and $39.53 \%$ when $\mathrm{pH}=9$, respectively (Figure 6c).

It can be seen that temperature significantly affects the release of nutrients. Higher temperature usually results in higher nutrient release rates. According to the slow release mechanism, ${ }^{24}$ temperature mainly affects the slow release performance of chemical fertilizers by affecting the film materials and the release rates of the nutrients. When the temperature is increased, the lignin microcapsules will be expanded, and the microcapsule wall will be destroyed, resulting in accelerated nutrient release rates. ${ }^{25}$ In addition, higher temperature leads to a more intense molecular motion in the solution, thus accelerating the rate of penetration of water molecules into the microcapsule membrane and the outward diffusion rate of nutrients.

After dissolution for 56 days, the weight loss rates of SRF were 66.16, 53.60 and $37.22 \%$ when the temperature was $5{ }^{\circ} \mathrm{C}$ (Figure 7a), 66.64, 59.90 and $38.10 \%$ when the temperature was $25^{\circ} \mathrm{C}$ (Figure 7b), and 73.39, 62.44 and $39.53 \%$ when the temperature was $45^{\circ} \mathrm{C}$ at the $\mathrm{pH}$ of 5,7 and 9 , respectively (Figure $7 \mathrm{c}$ ).
The release rate of fertilizers was accelerated under acidic environments. Unexpectedly, in the alkaline environment, the release rate of fertilizers was inhibited and the inhibitory effect became more significant with increasing temperature. There are a large number of ether bonds and methylene bonds in lignin urea-formaldehyde polymers. ${ }^{26} \mathrm{H}^{+}$easily breaks the ether bonds and hydrolyzes the methylene bonds, and the polymer molecular chain becomes shorter, reducing the thickness of the lignin microcapsule wall and thus decreasing the resistance for nutrient diffusion. ${ }^{27}$ In other words, lignin microcapsule film has better strength under alkaline conditions than under neutral and acidic conditions, and thus alkaline conditions can improve the steadiness of the capsule film and decrease the outward diffusion rate of nutrients. Weight loss rate is the percentage of decomposed fertilizer under the joint action of $\mathrm{pH}$ and temperature, which can comprehensively reflect the total release of nutrients. The above results implied that higher temperature and lower $\mathrm{pH}$ lead to a faster nutrient release of SRF.

\section{Slow release kinetics}

In order to investigate the mode of nutrient release from SRF, the release data were analyzed using the first order kinetics, Elovich and parabola equations. ${ }^{28}$ The equations corresponding to each model are presented in Table 1.
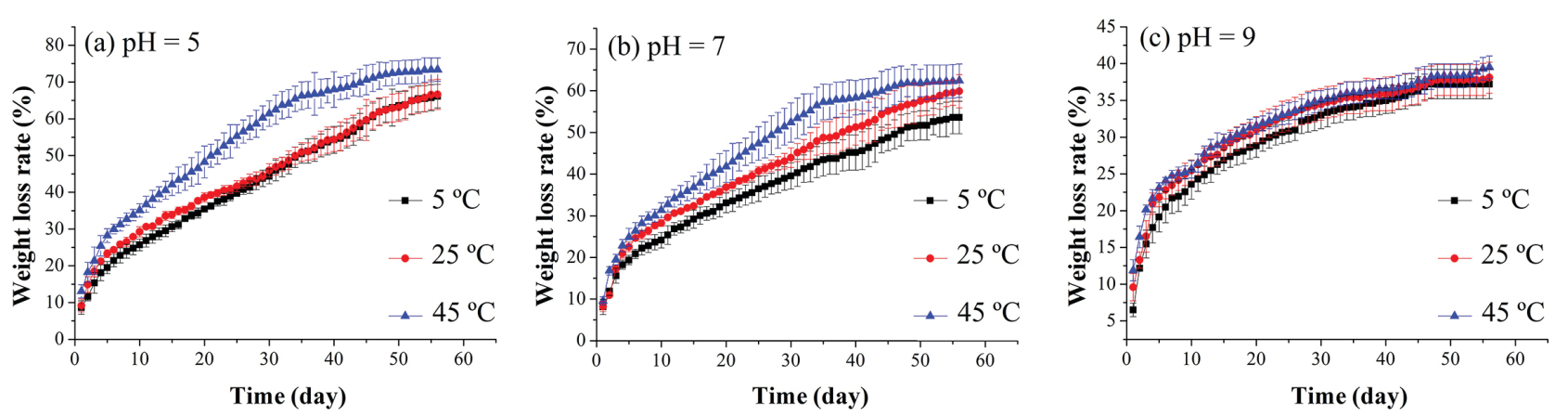

Figure 6. Influence of temperatures on weight loss rate at different pH: (a) 5; (b) 7; (c) 9. ..
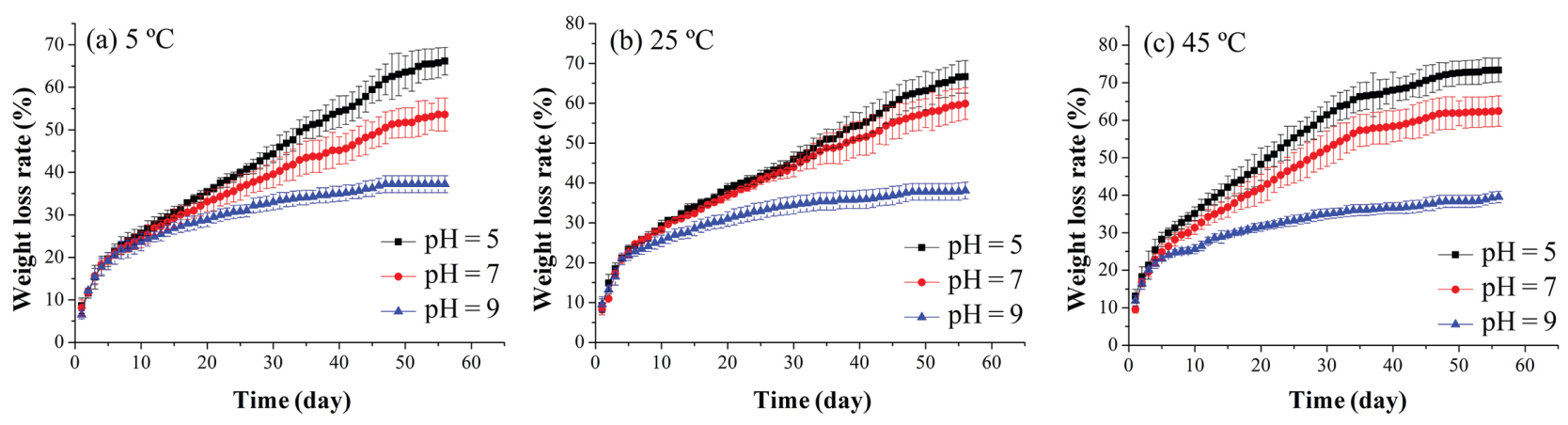

Figure 7. Influence of $\mathrm{pH}$ on weight loss rate at different temperature of (a) 5; (b) 25 and (c) $45^{\circ} \mathrm{C}$. 
Table 1. Mathematical forms of the kinetic models used

\begin{tabular}{lc}
\hline Kinetic model & Equation \\
\hline First order kinetics equation & $\mathrm{N}_{\mathrm{t}}=\mathrm{N}_{0}\left(1-\mathrm{e}^{-\mathrm{kt}}\right)$ \\
Elovich equation & $\mathrm{N}_{\mathrm{t}}=\mathrm{a}+\mathrm{bln} \mathrm{t}$ \\
Parabola equation & $\mathrm{N}_{\mathrm{t}}=\mathrm{a}+\mathrm{bt}^{0.5}$ \\
\hline
\end{tabular}

$\mathrm{N}_{\mathrm{t}}$ : fraction of nutrient released in $\mathrm{t}$ days (in percentage); $\mathrm{N}_{0}$ : maximum fraction of nutrient released during process; $\mathrm{k}, \mathrm{b}$ : rate constants; $\mathrm{t}$ : release time (in days); a: constant.

The kinetic parameters measured and calculated in order to describe the release behavior of SRF are shown in Table 2.

The first order kinetics equation provides the best correlation to describe the release mechanism of N, P and K into water and soil. The coefficient of determination $\left(\mathrm{R}^{2}\right)$ is greater than 0.970 . By comparing the rate parameters ( $\mathrm{k}$ and b), it can be found that the release rate of nutrients follows the order of $\mathrm{P}>\mathrm{K}>\mathrm{N}$ in water, while $\mathrm{P}>\mathrm{N}>\mathrm{K}$ in soil.

According to the data in Table 3 , the fitting degree was the highest when the weight loss rate was described by parabola equation, with all coefficients of determination greater than 0.920 for all assays. In Elovich equation and parabolic diffusion equation, the parameter $\mathrm{b}$ is the slope. Comparison of $b$ values also suggested that both temperature and $\mathrm{pH}$ can affect the release of SRF: higher temperature and lower $\mathrm{pH}$ usually lead to a faster release rate of SRF.

\section{Conclusions}

In summary, a new type of NPK compound SRF was produced by lignin-based microcapsules using formaldehyde to coat $\mathrm{K}_{2} \mathrm{HPO}_{4}$ and urea. The slow nutrient release of SRF can facilitate the continuous supply of nutrients for the plants, thereby preventing leaching losses commonly observed with traditional fertilizers. Our results show that the release of SRF is affected by temperature and $\mathrm{pH}$ : higher temperature and lower $\mathrm{pH}$ lead to a faster release of nutrients from the SRF. The effects of $\mathrm{pH}$ and temperature can be utilized to mediate the release properties of SRF for different types of soil and different seasons.

Table 2. Kinetic parameters of SRF under water and soil soaking

\begin{tabular}{|c|c|c|c|c|c|c|c|c|c|c|c|c|c|}
\hline \multirow{2}{*}{$\begin{array}{l}\text { Release } \\
\text { medium }\end{array}$} & \multirow{2}{*}{ Nutrient } & \multicolumn{4}{|c|}{$\mathrm{N}_{\mathrm{t}}=\mathrm{N}_{0}\left(1-\mathrm{e}^{-\mathrm{kt}}\right)$} & \multicolumn{4}{|c|}{$\mathrm{N}_{\mathrm{t}}=\mathrm{a}+\mathrm{b} \ln \mathrm{t}$} & \multicolumn{4}{|c|}{$\mathrm{N}_{\mathrm{t}}=\mathrm{a}+\mathrm{bt}^{0.5}$} \\
\hline & & $\mathrm{N}_{0} / \%$ & $\mathrm{k}$ & $\mathrm{R}^{2}$ & SE & $\mathrm{a}$ & $\mathrm{b}$ & $\mathrm{R}^{2}$ & SE & $\mathrm{a}$ & $\mathrm{b}$ & $\mathrm{R}^{2}$ & SE \\
\hline \multirow{3}{*}{$\begin{array}{l}\text { Distilled } \\
\text { water }\end{array}$} & $\mathrm{N}$ & 95.23 & 0.206 & 0.978 & 1.755 & 34.40 & 17.41 & 0.947 & 4.691 & 29.89 & 11.24 & 0.733 & 8.319 \\
\hline & $\mathrm{P}$ & 95.51 & 0.291 & 0.993 & 0.977 & 40.32 & 16.55 & 0.865 & 7.802 & 36.19 & 10.50 & 0.570 & 11.03 \\
\hline & $\mathrm{K}$ & 95.35 & 0.208 & 0.995 & 0.858 & 29.71 & 19.04 & 0.929 & 5.667 & 27.74 & 11.67 & 0.714 & 9.041 \\
\hline \multirow{3}{*}{ Soil } & $\mathrm{N}$ & 82.22 & 0.090 & 0.995 & 0.424 & 0.273 & 21.33 & 0.978 & 2.901 & 4.282 & 12.08 & 0.924 & 4.302 \\
\hline & $\mathrm{P}$ & 96.69 & 0.107 & 0.971 & 3.094 & 0.217 & 26.07 & 0.942 & 5.863 & 6.765 & 14.34 & 0.836 & 7.842 \\
\hline & $\mathrm{K}$ & 92.74 & 0.086 & 0.981 & 2.556 & -2.73 & 25.34 & 0.957 & 4.844 & 4.002 & 13.90 & 0.865 & 6.779 \\
\hline
\end{tabular}

$\mathrm{N}_{\mathrm{t}}$ : fraction of nutrient released in $\mathrm{t}$ days (in percentage); $\mathrm{N}_{0}$ : maximum fraction of nutrient released during process; $\mathrm{k}$, b: rate constants; t: release time (in days); a: constant; $\mathrm{R}^{2}$ : coefficient of determination; SE: standard error.

Table 3. Kinetic parameters of SRF at different temperatures and $\mathrm{pH}$ values

\begin{tabular}{|c|c|c|c|c|c|c|c|c|c|c|c|c|c|}
\hline \multirow{2}{*}{$\begin{array}{l}\text { Temperature / } \\
{ }^{\circ} \mathrm{C}\end{array}$} & \multirow{2}{*}{$\mathrm{pH}$} & \multicolumn{4}{|c|}{$\mathrm{N}_{\mathrm{t}}=\mathrm{N}_{0}\left(1-\mathrm{e}^{-\mathrm{kt}}\right)$} & \multicolumn{4}{|c|}{$\mathrm{N}_{\mathrm{t}}=\mathrm{a}+\mathrm{b} \ln \mathrm{t}$} & \multicolumn{4}{|c|}{$\mathrm{N}_{\mathrm{t}}=\mathrm{a}+\mathrm{bt}^{0.5}$} \\
\hline & & $\mathrm{N}_{0} / \%$ & $\mathrm{k}$ & $\mathrm{R}^{2}$ & SE & $\mathrm{a}$ & $\mathrm{b}$ & $\mathrm{R}^{2}$ & SE & $\mathrm{a}$ & $\mathrm{b}$ & $\mathrm{R}^{2}$ & SE \\
\hline \multirow{3}{*}{5} & 5 & 75.124 & 0.034 & 0.949 & 3.122 & 2.000 & 11.469 & 0.936 & 1.450 & -3.217 & 9.111 & 0.986 & 0.770 \\
\hline & 7 & 53.120 & 0.053 & 0.927 & 1.38 & -1.958 & 12.749 & 0.930 & 1.512 & 2.958 & 6.793 & 0.996 & 0.281 \\
\hline & 9 & 35.387 & 0.109 & 0.907 & 0.448 & 6.075 & 7.843 & 0.995 & 0.227 & 10.267 & 3.948 & 0.950 & 0.649 \\
\hline \multirow{3}{*}{25} & 5 & 67.729 & 0.045 & 0.912 & 2.429 & -3.933 & 15.709 & 0.898 & 2.287 & 1.583 & 8.478 & 0.987 & 0.679 \\
\hline & 7 & 58.772 & 0.055 & 0.922 & 1.511 & -2.019 & 14.228 & 0.937 & 1.596 & 3.668 & 7.542 & 0.993 & 0.438 \\
\hline & 9 & 35.799 & 0.135 & 0.886 & 0.409 & 9.261 & 7.275 & 0.994 & 0.222 & 13.365 & 3.619 & 0.927 & 0.727 \\
\hline \multirow{3}{*}{45} & 5 & 74.979 & 0.059 & 0.953 & 1.363 & -2.030 & 18.378 & 0.943 & 1.933 & 5.648 & 9.676 & 0.987 & 0.786 \\
\hline & 7 & 63.216 & 0.063 & 0.947 & 1.119 & -0.478 & 15.461 & 0.953 & 1.472 & 6.236 & 8.089 & 0.985 & 0.718 \\
\hline & 9 & 36.143 & 0.149 & 0.808 & 0.482 & 11.330 & 6.862 & 0.993 & 0.242 & 14.972 & 3.459 & 0.951 & 0.563 \\
\hline
\end{tabular}

$\mathrm{N}_{\mathrm{t}}$ : fraction of nutrient released in $\mathrm{t}$ days (in percentage); $\mathrm{N}_{0}$ : maximum fraction of nutrient released during process; $\mathrm{k}$, b: rate constants; t: release time (in days); a: constant; $\mathrm{R}^{2}$ : coefficient of determination; SE: standard error. 
Based on various characterization data, the prepared SRF exhibited good slow-release properties. Analysis of the NPK release kinetics in water and soil revealed that the formulation basically follows the first order kinetics equation, with the coefficients greater than 0.970 for all assays. Also, the product with good slow release properties could be particularly important in agricultural production.

\section{Acknowledgments}

This study was financially supported by Fundamental Research Funds for the Central Universities (project 2662017JC045), the open funds of the State Key Laboratory of Agricultural Microbiology (project No. AMLKF201610), Science and Technology Program of Wuhan, China (No. 2016020101010091).

\section{References}

1. Cohen, J. E.; How Many People Can the Earth Support?; Wiley: New York, USA, 1996, p. 18.

2. Araújo, B. R.; Romão, L. P. C.; Doumer, M. E.; Mangrich, A. S.; J. Environ. Manage. 2017, 190, 122.

3. Calabria, L.; Vieceli, N.; Bianchi, O.; Rv, B. D. O.; Do, N. F. I.; Schmidt, V.; Ind. Crops Prod. 2012, 36, 41.

4. Azeem, B.; Kushaari, K.; Man, Z. B.; Basit, A.; Thanh, T. H.; J. Controlled Release 2014, 181, 11.

5. Wen, P.; Wu, Z.; He, Y.; ACS Sustainable Chem. Eng. 2016, 4, 6572.

6. Teodorescu, M.; Lungu, A.; Stanescu, P. O.; Ind. Eng. Chem. Res. 2009, 48, 6527; Liang, R.; Liu, M.; Ind. Eng. Chem. Res. 2006, 45,8610 .

7. Chawakitchareon, P.; Anuwattana, R.; Buates, J.; Advanced Materials: Manufacturing, Physics, Mechanics and Applications; Springer: Azov, Russia, 2016, p. 129; Wu, L.; Liu, M.; Ind. Eng. Chem. Res. 2007, 46, 6494.

8. Yang, Y.; Zhang, M.; Li, Y. C.; Soil Sci. Soc. Am. J. 2012, 76, 2307.
9. Xie, L.; Liu, M.; Ni, B.; Wang, Y.; J. Agric. Food Chem. 2012, $60,6921$.

10. França, A. A.; Schultz, J.; Borges, R.; Wypych, F.; Mangrich, A. S.; J. Braz. Chem. Soc. 2017, 28, 2211.

11. Wen, P.; Han, Y.; Wu, Z.; Arab. J. Chem. 2017, 10, 922.

12. Wen, P.; Wu, Z.; Han, Y.; ACS Sustainable Chem. Eng. 2017, 5,7374 .

13. Mohammed, M. R.; Jiro, T.; Motiur, R.; Chem. Ecol. 2013, 29, 540.

14. Behin, J.; Sadeghi, N.; Int. J. Recycl. Org. Waste Agric. 2016, $5,289$.

15. Li, W. Z.; Wang, J. L.; Gao, M. X.; J. Nanjing For. Univ., Nat. Sci. Ed. 2013, 37, 91.

16. Jiao, G. J.; Xu, Q.; Cao, S. L.; BioResources 2018, 13, 1711.

17. Champagne, C. P.; Fustier, P.; Curr. Opin. Biotechnol. 2007, $18,184$.

18. Rathore, S.; Desai, P. M.; Liew, C. V.; Chan, L. W.; Heng, P. W. S.; J. Food Eng. 2013, 116, 369.

19. Bashan, Y.; Appl. Environ. Microbiol. 1986, 51, 1089.

20. OriginPro 8.5, OriginLab, Northampton, USA, 2010.

21. Wen, J. L.; Xue, B. L.; Xu, F.; Sun, R. C.; Pinkert, A.; Ind. Crops Prod. 2013, 42, 332; Faix, O.; Holzforschung 1991, 45, 21; Fujioka, Y.; Bull. Iron Steel Inst. Jpn. 2014, 19, 173.

22. Zhao, S. Y.; Zhou, H. R.; Zhao, R.; Chem. Adh. 2011, 33, 35 (in Chinese). Available at http://en.cnki.com.cn/Article_en/ CJFDTotal-HXYZ201102012.htm, accessed in June 2018.

23. Hatakeyama, H.; Suzuki, K.; Nakano, J.; Vacuum 1968, 71, 247.

24. Gambash, S.; Kochba, M.; Avnimelech, Y.; Soil Sci. 1990, 150, 446.

25. Duan, L. L.; Zhang, M.; Liu, G.; Yang, Y. C.; Yang, Y.; J. Soil Water Conserv. 2009, 23, 71 .

26. Abreu, H. D. S.; Nascimento, A. M. D.; Maria, M. A.; Wood Fiber Sci. 1999, 31, 426.

27. Han, J. H.; Meng, X. Z.; Henan Chem. Ind. 1996, 1, 35.

28. Shariatmadari, H.; Shirvani, M.; Jafari, A.; Geoderma 2006, 132,261 .

Submitted: May 8, 2018

Published online: June 19, 2018 